University of Nebraska - Lincoln

DigitalCommons@University of Nebraska - Lincoln

Faculty Publications from Nebraska Center for Research on Children, Youth, Families, and Schools
Children, Youth, Families \& Schools, Nebraska Center for Research on

2007

\title{
Using a Creative Intervention to Increase Self-Disclosure Among Mandated Juveniles with Co-Occurring Disorders
}

\author{
Faith Drew \\ Texas Tech University Health Sciences Center \\ George W. Bitar \\ Texas Tech University \\ Robert Gee \\ Texas Tech University Health Sciences Center \\ Chad Graff \\ Texas Tech University \\ Paul R. Springer \\ University of Nebraska at Lincoln, pspringer3@unl.edu
}

Follow this and additional works at: https://digitalcommons.unl.edu/cyfsfacpub

Part of the Pre-Elementary, Early Childhood, Kindergarten Teacher Education Commons

Drew, Faith; Bitar, George W.; Gee, Robert; Graff, Chad; and Springer, Paul R., "Using a Creative Intervention to Increase Self-Disclosure Among Mandated Juveniles with Co-Occurring Disorders" (2007). Faculty Publications from Nebraska Center for Research on Children, Youth, Families, and Schools. 5. https://digitalcommons.unl.edu/cyfsfacpub/5

This Article is brought to you for free and open access by the Children, Youth, Families \& Schools, Nebraska Center for Research on at DigitalCommons@University of Nebraska - Lincoln. It has been accepted for inclusion in Faculty Publications from Nebraska Center for Research on Children, Youth, Families, and Schools by an authorized administrator of DigitalCommons@University of Nebraska - Lincoln. 


\title{
Using a Creative Intervention to Increase Self-Disclosure Among Mandated Juveniles with Co-Occurring Disorders
}

\author{
Faith Drew \\ George W. Bitar \\ Robert Gee \\ Chad Graff \\ Paul Springer
}

\begin{abstract}
Counselors providing treatment within the juvenile justice system encounter numerous challenges that are inherent in working with this population. One of the challenges includes providing treatment to adolescents who are entering the juvenile justice system with co-occurring mental health and substance use disorders. Given the challenges, creative interventions that cnhance client motivation and the therapeutic relationship are especially needed. The purpose of this article is to propose a creative intervention that may enhance the therapcutic relationship,
\end{abstract}

Faith Drew is Assistant Director, Employee Assistance Program, Department of Neuropsychiatry, Texas Tech University Health Sciences Center; also she is a doctoral candidate in the Marriage and Family Therapy Program, Deparıment of Applied and Professional Studies, College of Human Sciences, Texas Tech University, Lubbock, TX.

George W. Bitar, Chad Graff, and Paul Springer are doctoral candidates, Marriage and Family Therapy Program, Department of Applied and Professional Studies, College of Human Sciences, Texas Tech University, Lubbock, TX.

Robert Gee is Assistant Professor, Department of Neuropsychiatry and Behavioral Science, Texas Tech University Health Sciences Center, Lubbock, TX.

Address correspondence to: Faith Drew, Department of Neuropsychiatry and Behavioral Science, Texas Tech University Health Sciences Center, 3601 4th Street STOP 8103, Lubbock, TX 79430-8130 (E-mail: faith.drew@ttuhsc.edu).

Journal of Creativity in Mental Health, Vol. 2(2) 2006/2007

Available online at http://jcmh.haworthpress.com

(C) 2006/2007 by The Haworth Press, Inc. All rights reserved. doi: $10.1300 / \mathrm{J} 456 \mathrm{v} 02 \mathrm{n} 02 \_06$ 
increase client investment in treatment, and facilitate client self-disclosure. A case illustration will be used to illustrate the intervention. doi:10.1300/J456v02n02_06 [Article copies available for a fee from The Haworth Document Delivery Service: I-800-HAWORTH. E-mail address: $<$ docdelivery@haworthpress.com> Website: <http://www.HaworthPress.com> (C) 2006/2007 by The Haworth Press. Inc. All rights reserved.]

KEYWORDS. Self-disclosure, mental health, substance abuse, juvenile justice, counseling, co-occurring disorder

Working with mandated juveniles in the criminal justice system may be a challenge for behavioral health professionals (e.g., counselors, therapists, social workers). For counselors who work with this population, treatment can sometimes be challenging as clients may appear distrusting and ambivalent about the need to change. Given the challenges inherent in working with mandated juvenile populations, creative interventions that enhance client motivation and the therapeutic relationship are especially needed. The purpose of this article, therefore, is to propose a creative intervention for use with mandated juvenile justice populations with behavioral health disorders. The proposed intervention can be used to enhance the therapeutic relationship, facilitate client self-disclosure, and increase client investment in counseling.

Prior to describing the proposed creative intervention, a brief description of adolescents with co-occurring mental health and substance use disorders within the juvenile justice system will be presented in order to establish the scope of the problem. Next, the significance of selfdisclosure will be examined as it relates to this intervention. Furthermore, an explanation about the levels of client investment (e.g., compliance to investment) will be described within the context of this intervention. Finally, a case example will be provided to illustrate the intervention.

\section{DESCRIPTION OF POPULATION IN MANDATED TREATMENT}

Co-occurring mental health and substance use disorders (COD) among children and adolescents present special challenges for our society. According to data gathered by the Northwestern Juvenile Project (Abram, Dulcan, McClelland, Teplin, \& Washburn, 2006), more than 10\% of adolescent males and $13.7 \%$ of adolescent females in the United States meet the criteria for COD. Due to the extent and variety of mental disorders, 
a full discussion of each one in this article is prohibitive. However, major disorders relevant for youth with COD include: mood disorders (e.g., Major Depressive Disorder), anxiety disorders, and attention-deficit and disruptive behavior disorders (e.g., Attention-Deficit/Hyperactivity Disorder, Conduct Disorder, and Oppositional Defiant Disorder).

\section{Mental Disorders}

Estimates of the prevalence of mental disorders in American youth range anywhere from $16 \%$ to $22 \%$ (Costello, Dulcan, Edelbrock, Kalas, \& Klaric, 1996). In general, one in five children (20\%) is estimated to have a mental disorder with mild functional impairment (U S. Department of Health and Human Services, 1999; U. S. Department of Health and Human Services, Substance Abuse and Mental Health Services Administration, 1999). Federal regulations also define a sub-population of children and adolescents that have more severe functional limitations or a "serious emotional disturbance" (SED). Unfortunately, investigators estimate that about 3.6 million American children (5\%) live with SED. Furthermore, according to the Northwestern Juvenile Project study, nearly twothirds of males and three-quarters of females meet diagnostic criteria for one or more psychiatric disorders; many of these youth had two or more disorders (Teplin, Abram, McClelland, Dulcan, Washburn, 2006).

\section{Substance-Related Disorders}

Investigators from the Monitoring the Future (MTF) study report that extraordinarily high levels of illicit drug use by American youth during the last third of the twentieth century (Bachman, Johnston, O'Malley, \& Schulenberg, 2005). In 1975, when the MTF survey began, a majority of youth $(55 \%)$ had used an illicit drug by the time they left high school. By 1981 , this figure had risen to $66 \%$. After a long and gradual decline, to a low of $41 \%$ in 1992, the percentage had again risen, standing at $51 \%$ in 2004. This translates to 36.5 million American youth that have used an illicit drug before they leave high school. However, the MTF survey does not consider diagnostic criteria for substance use disorders and reflects only the use of illicit substances.

Clearly, the rate of COD among the youth population warrants attention. If providers fail to treat one disorder, both disorders usually become more severe (New Freedom Commission on Mental Health, 2003). Additional complications frequently happen for youth with COD, including the risk for medical problems, trauma, sexual and physical abuse, broken 
relationships, homelessness, incarceration, hopelessness, loneliness, despair, and suicide (Kandel et al., 1999; Keller, Lavori, Wunder, \& Hasin, 1992; Zeitlin, 1999). In summary, strong scientific evidence supports the premise that children and adolescents with COD represent a major public health concern and is a matter with potentially devastating human, social, and economic consequences (Dickey, Normand, Weiss, Drake, \& Azent, 2002; United States Public Health Service, 1999; World Health Organization, 2001).

Many of these children and adolescents with mental illness and substance-related disorders will eventually end up in the juvenile justice system due to the lack of services received prior to an offense (Bonham, 2006). Once in the juvenile justice system, behavioral health treatment is often mandated in an attempt to improve client functioning and reduce recidivism. Counselors who provide treatment within this population are often faced with myriad challenges, including facilitating client self-disclosure, building a therapeutic alliance, enhancing client motivation, and negotiating the sometimes conflicting goals between the juvenile justice and behavioral health systems.

\section{Self-Disclosure in Treatment}

One of the goals of this intervention is to facilitate client self-disclosure. Implementing activities and interventions that facilitate client selfdisclosure are important for two reasons: (a) Evidence suggests that therc are numerous psychological and physiological benefits of self-disclosure (e.g., Farber, 2006; Francis \& Pennebaker, 1992; Pennebaker \& Beall, 1986; Pennebaker, Kiecolt-Glaser, \& Glaser, 1988; Petrie \& Booth, 1995) and (b) all behavioral health models rely on some degree of client self-disclosure for effective assessment and treatment. Not surprisingly, research suggests that the therapeutic alliance and counselor self-disclosure are central to the emotional saliency of client self-disclosures (Farber \& Hall, 2002; Farber, 2006).

The Johari window provides a useful way to conceptualize ranges of secrecy and disclosure (Farber, 2006). The window has four quadrants. The first quadrant includes that information which is known to both oneself and others (Open Self). The second quadrant includes that information which is not known to others but is known to oneself (Hidden Self). The third quadrant includes that information which is not known to oneself but is known to others (Blind Self), and the fourth quadrant includes that information which is not known to oneself or others (Unknown Self). 
While the Johari window is limited in its ability to capture the complexity of disclosurc processes, the model is a helpful way to establish a general conceptualization of conscious and unconscious dynamics related to disclosure. One of the purposes of this activity is to implement a creative method of expanding the first quadrant (Open Self) while bringing greater awareness to the second quadrant (Hidden Self) and minimizing the third and fourth quadrants (Blind Self, Unknown Self). This activity also provides an opportunity for counselors to self-disclose, thus modeling appropriate disclosing behaviors for clients.

\section{Compliance and Internalization}

Another goal of the proposed activity is to increase client investment in therapy. Shearer (2005) describes two important concepts that are important to distinguish when discussing the level of client investment in treatment: compliance and internalization. Compliance involves conforming to the influence of another person or group, not because of the perceived benefits of change, but due to external punishments and rewards. Compliant behaviors within the mandated treatment may include a client attending required sessions and participating at a depth sufficient to appease those in power. Internalization, on the other hand, refers to a client's belief that new behaviors will be intrinsically rewarding. Instead of being motivated by issues of compliance, therefore, the client is motivated by the rewards that result from the changes themselves. While described as distinct categories, it is important to note that the author explains that clients often begin treatment in a compliant stage and move toward internalization as treatment progresses.

The movement from compliance to internalization also overlaps conceptually with Prochaska's (1999) stages of change model. This transtheoretical approach was developed in the common factors movement, which sought to identify change processes that were common across psychotherapy models. The stages of change are as follows: (a) pre-contemplation (client not intending to make a change); (b) contemplation (more aware of pros of changing but more acutely aware of cons); (c) preparation (action is planned in the immediate future); (d) action (specific, overt modifications have been made); (e) maintenance (work is to prevent relapse); and (f) termination (individuals experience complete self-efficacy; confident that they will not return to old patterns). While presented in a linear manner, the stages are actually much more fluid in nature, since 
clients might move forward and then slide back to previous stages or skip stages altogether.

The compliance-internalization continuum and the preparation-maintenance continuum may have influences on the self-disclosure process. Clients in the compliance/precontemplation stage are probably unlikely to self-disclose or express emotional vulnerability, perhaps not seeing the potential benefit of counseling. As mentioned, mandated clients usually begin on this end of the continuum, where the therapeutic relationship is in its infancy and disclosures may be about superficial topics and serve as a way to pass time. Ideally, as treatment progresses and the therapeutic alliance develops, clients begin to see the intrinsic rewards in changing and self-disclosures become increasingly salient.

\section{USING UNO AS A CREATIVE INTERVENTION WITH JUVENILES}

\section{Case Study}

The purpose of this activity is to: (a) facilitate client self-disclosure; (b) promote the therapeutic alliance; and (c) increase client investment in the therapeutic process. When clients begin discussing emotional events and exploring meanings related to the events, this creative intervention can be used as a catalyst to enhance insight and growth.

Setting the stage. When working with juvenile offenders with COD, it is important to understand that the hesitancy and resistance often seen in the counseling session works as a protective factor for many of these troubled youth. From the moment of incarceration, many are faced with the loss of their freedom, loss of employment, loss of choice, and loss of their family members and friends (Gee, Springer, Bitar, Drew, \& Graff, 2005). Many of these individuals, however, rarely talk openly about this loss and the emotions associated with any trauma, having trepidations of being portrayed as vulnerable or weak. Patience on behalf of the counselor when utilizing this activity, therefore, is often required.

Materials. The following items are needed for the exercise:

1. Full deck of UNO cards

2. Crayons

3. Paper 
Instructions. At the beginning of the session, the counselor should introduce the idea of the UNO game activity, explaining how this game is a way of creating a more informal therapeutic session. The counselor asks the clients if they know how to play UNO. If necessary, the counselor can explain the rules of the UNO game to lay a foundation for play.

UNO is a card game (a Mattel product) with a special printed deck consisting of cards of four different colors. There are three special playing cards labeled "skip," "draw two," and "reverse," and two special black cards labeled "wild" and "wild draw four." The UNO card game is designed for two or more players at least 5 years old or older. The UNO card game combines chance and the mindful strategy of knowing which card to play to increase the chance of winning. At the beginning of the game, the card dealer will shuffle the cards and deal seven cards (face down) to each player. Once each player has seven cards the dealer puts the deck down (face down) and the top card is turned over in the discard pile to start the play. The players must match the number or color of the top card in the discard pile with a card in their hand. If no number or color matches, the player has the option to play a wild card (if the player has one in his or her hand) or to draw a card from the stack. Each player takes a turn in clockwise order (unless a "reverse" card is played, and then the play continues in the opposite direction). When a player has only one card, the player must say "UNO." If another player calls out "UNO" first, then the player with only one card must draw two cards as a penalty. The game ends when a player is able to discard all cards in his or her hand.

UNO is a creative intervention because the basic rules of play allow modifications to be made, turning the regular card game into a therapeutic intervention. The colors are symbolic of experienced emotions. The players can discuss personal experiences and feelings in the context of a game.

Once the client and counselor are familiar with the original version of the game, therapeutic modifications to the game can be added. The counselor will introduce the use of emotions as a central feature of this game. Each color in the deck (i.e., red, yellow, green, blue) represents a specific emotion. The counselor and client must discuss and select specific emotions to represent each color card. After the client and counselor collaborate and determine which emotion represents each color card, a key or legend can be created. Either the counselor or client can use the crayons and paper to create a workable key (which will stay in front of the players while the game is played). The game is played similarly to the original card game; however, when a color card is played, the person playing the card must describe a time when he or she felt the 
assigned emotion. The player may modify the response to explain personal feelings that encompass any person, place, or event in the past, present, or future. For example, a client may report feeling angry when his/her mother does not attend family therapy sessions.

At this point, the counselor must be willing to self-disclose and model healthy emotional expression, describing his/her personal emotions. Although the participation of the counselor is crucial, the counselor may modify his/her responses appropriate to the age group and interests of the client. Modeling healthy self-disclosure is an important element, since people in the adolescent's life may not disclose personal feelings in an appropriate manner. Additionally, as the therapist displays vulnerability by agreeing to fully participate, the client may be more likely to respond in a more vulnerable manner. As with any disclosure, the counselor must be sure that his/her own vulnerability adds to the therapeutic context and does not distract from the therapeutic process. During this process, the counselor may choose to ask clarifying questions and use reflective comments during the adolescent's disclosure.

\section{THE THERAPEUTIC CARD GAME: CASE EXAMPLE}

The following is an example of how this activity was applied to therapeutic sessions with a juvenile offender with COD. In this case example, the juvenile was completing his six-month sentence in a juvenile justice facility in the West Texas Region. ${ }^{1}$

\section{Lewis}

Lewis, an African American 14-year-old male, had already spent numerous months in and out of various juvenile treatment programs by the time I met him. His latest incarceration was due to a theft charge and probation violation as a result of illegal use of substances. Once I was assigned to Lewis' case, I received his paperwork which included diagnostic impressions. Lewis was diagnosed with Adjustment Disorder with Anxious Mood, Conduct Disorder Adolescent-Onset Type, Cannabis Abuse, and Cocaine Abuse on Axis I. No diagnosis on Axis II was reported. He did not report any significant medical or physical problems on Axis III; in contrast, Axis IV reflected several psycho-social stressors. Upon meeting Lewis for the first time, I was able to get an adequate description of the stressors he experienced. He had very little family support; as 
the second oldest child out of four, each sibling had a different father. In his case, when he was only two months old, his biological father left. Furthermore, his younger sibling's biological father (the man whom Lewis calls "father") was currently serving a 12-year prison sentence. His mother, an African American 32-year-old, had also spent time in and out of jail and was currently finishing a sentence while I worked with Lewis. Besides his family-of-origin issues, Lewis was concerned that he may be a father himself.

In the beginning, Lewis seemed resistant to therapy. However, as we continued to meet on a weekly basis, Lewis seemed increasingly invested. His investment seemed to grow as he began to trust me and the therapy process. We were able to use self-disclosure as a way to build the therapeutic relationship. In addition, the creative intervention helped to increase self-disclosure by providing an avenue of talking about issues in a creative way.

Treatment consisted of weekly group and individual counseling sessions. Family therapy sessions, involving the maternal grandmother or mother (once she finished her sentence), were conducted every other week. During our individual sessions, I introduced the UNO game. I used this intervention for three sessions over the course of treatment which totaled 20 individual 30-minute sessions. Lewis and I agreed on using "angry," "happy," "hurt," and "frustrated" feelings whenever we played a color card. The "angry," "happy," and "frustrated" experiences seemed casy for Lewis to describe, however, it appeared difficult for him to discuss "hurt." As therapy progressed, Lewis was more inclined to freely share his emotions and it was easier to ask him to expand on why he felt the way he did. In fact, Lewis reported that it was easier for him to show anger than it was to express his hurt because the hurt represented vulnerability and anger was a way to keep him protected. In addition, Lewis described how he had been disappointed by his family and if he did not show that he cared then he would not feel hurt or sad. It seemed during the course of treatment that Lewis was moving from a place of compliance to a place of personal investment in counseling.

As the counselor, I felt this was a tremendous improvement for Lewis. He was able to express his emotional experience in a safe environment. In addition, he experienced a reciprocal process because he was able to hear my personal emotional experiences. Vulnerability was modeled and shared between Lewis and myself, which strengthened the therapeutic process.

As therapy advanced, I was able to challenge him in ways that he would not allow in previous treatments. Progress with Lewis was slow; 
however, he became more self-aware and reflective. In one memorable session, Lewis said that he liked therapy because it was helping him talk about issues that he had never shared in the past. Furthermore, Lewis admitted that therapy provided a safe place for him to challenge himself to work on painful issues that he would not have faced if he did not feel connected with the counselor. Throughout the therapeutic process it became clear that Lewis felt supported and heard. He seemed to feel empowered and supported through the use of the creative intervention because we shared vulnerable moments and met them by taking an empathic stance. This therapeutic process allowed Lewis an opportunity to: (a) self-disclose his emotions surrounding family of origin issues; (b) facilitate the development of more intrapersonal reflection and awareness; and (c) increase feelings of connection that would, hopefully, carry over to other relationships outside the therapy process.

Using the UNO card game as a creative intervention by modifying the original rules of the game allows counselors a new and creative way to tap into clients' emotions and encourage self-disclosure. While it is not possible to determine how much change within the client can be credited to the therapeutic relationship, versus the creative intervention itself, my experience with this intervention suggests it can facilitate the therapeutic process. Additionally, a therapist's own disclosure in the context of this creative intervention can be viewed as a way to lessen the hierarchy between the counselor and client, thus creating a more collaborative and equal therapeutic relationship. This is consistent with progressive multicultural (Arredondo et al., 2006; Sue \& Sue, 1996) and relational models of development (Jordan, 1996; Miller \& Stiver, 1997).

In conclusion, this creative intervention is proposed as a way to facilitate self-disclosure among adolescents with co-occurring mental health and substance use disorders. Additionally, the use of counselor self-disclosure during this intervention may have a significant effect, as counselors model appropriate ways to disclose while creating more collaborative treatment contexts. Creative interventions, such as using UNO as described, may also help increase a client's investment in treatment. Counselors are encouraged to integrate this and other creative interventions in their work with this population.

\section{NOTE}

1. Note that a fictional name is used to respect client confidentiality in the following illustration. 


\section{REFERENCES}

Arredondo, P., Toponek, R., Brown, S. P., Jones, J., Locke, D. C., Sanchez, J. et al. (1996). Operationalization of the multicultural counseling competencies. Joumal of Multicultural Counseling and Development, 24, 42-78.

Bonham, E. (2006). Adolescent mental health and the juvenile justice system. Pediatric Nursing, 32, 591-595.

Costello A. J., Edelbrock C. S., Dulcan M. K., Kalas R., Klaric S. H. (1996). Development and testing of the NIMH diagnostic interview schedule for children in a clinic population: Final report. Rockville, MD: NIMH Center for Epidemiologic Studies.

Dickey, B., Normand, S. T., Weiss, R. D., Drake, R. E., \& Azent, H. (2002). Medical mortality, mental illness, and substance use disorders. Psychiatric Services, 53, 861-867.

Farber, B. (2006). Self-disclosure in psychotherapy. New York: The Guillord Press.

Farber, B. A., \& Hall, D. (2002). Disclosure to therapists: What is and is not discussed in psychotherapy. Journal of Clinical Psychology, 58. 359-370.

Francis, M. E., \& Pennebaker. J. W. (1992). Putting stress into words: The impact of writing on physiological, absentec, and self-reported emotional well-bcing measures. American Joumal of Health Promotion, 6(4), 280-287.

Gee, R., Springer, P., Bitar, G., Drew, F., \& Graff, C. (2005). Keeping the music alive: Using the "Grief and Hope Box" with adult offenders with co-occurring mental health and substance use issues. Journal of Creativity in Mental Health, 1(3/4), 185204.

Johnston L. D., O'Malley P. M., Bachman J. G., Schulenberg J. E. (2005). Monitoring the future national survey results on drug use, 1975-2004: Volume I, Secondary school students. Bethesda, MD: National Institute on Drug Abuse.

Jordan. J. (1996). Relational Therapy in a Non-Relational World. Retrieved December 8, 2006, from the Wellesley Centers for Women Web site: http://www.wcwonline. $\mathrm{org} /$ pubs/title.php?id=256\&title=Relational

Kandel, D. B., Johnson, J. G., Bird, H. R., Weissman M. M., Goodman, S. H., Lahey, B. B. (1999). Psychiatric comorbidity among adolescents with substance use disorders: Findings from the MECA study. Journal of the American Academy of Child Adolescent Psychiatry, 38, 693-699.

Keller. M. B., Lavori, P. W., Beardslee, W.. Wunder. J., Hasin, D. (1992). Clinical course and outcome of substance abuse disorders in adolescents. Journal of Substance Abuse Treatment, 9(1), 9-14.

Miller, J., \& Stiver, I. (1997). The healing connection: How women form relationships in therapy and in life. Boston: Beacon.

New Freedom Commission on Mental Health. (2003). In: Achieving the promise: Transforming mental health care in America - final report. Rockville, MD: Author.

Pennebaker. J. W., \& Beall, S. K. (1986). Confronting a traumatic event: Toward an understanding of inhibition and disease. Journal of Abnormal Psychology, 95, 274-281.

Penncbaker, J. W., Kiecolt-Glaser, J. K., \& Glaser, R. (1988). Disclosure of traumas and immune function: Health implications for psychotherapy. Journal of Consulting and Clinical Psychology, 56, 239-245. 
Petrie, K., \& Booth, R. (1995). Disclosure of trauma and immune response to a Hepatitis B vaccination program. Journal of Consulting and Clinical Psychology; 63. 787-793.

Prochaska, J. (1999). How do people change? In M. Hubble. B. Duncan. \& S. Miller (Eds.), The heart and soul of change: What works in psychotherapy (pp. 227-258). Washington DC: American Psychological Association.

Shearer, R. (2005). Treatment motivation characteristics of offenders who abuse substances. In B. Sims (Ed.), Substance abuse counseling with correctional clients: Practical implication for institutional and community setting (pp. 39-56). New York: Haworth.

Sue, D., \& Sue, D. W. (2003). Counseling the culturally diverse: Theory and practice $\left(4^{\text {th }}\right.$ ed.). New York: Wiley.

Teplin, L. A., Abram, K. M., McClelland, A. A., Dulcan, M. K.. \& Washburn, J. (2006). Psychiatric disorders of youth in detention. Juvenile Justice Bulletin. Office of Juvenile Justice and Delinquency Prevention, Washington DC: Office of Justice Programs, U.S. Department of Justice.

United States Public Health Service. (1999). The surgeon general's call to action to prevent suicide. Washington, DC: Author.

U. S. Department of Health and Human Services, Substance Abuse and Mental Health Services Administration. (1999). The relationship between mental health and substance abuse among adolescents. Rockville, MD: Author.

U. S. Department of Health and Human Services. (1999). Mental health: A report of the surgeon general. Rockville, MD: Author.

World Health Organization. (2001). The world health report. In Mental Health: New Understanding, New Hope. Geneva. Switzerland: Author.

Zeitlin, H. (1999). Psychiatric comorbidity with substance misuse in children and teenagers. Drug and Alcohol Dependence, 55, 225-234.

RECEIVED: 02/13/07

REVISED: 05/25/07

ACCEPTED: 05/31/07

doi:10.1300/J456v02n02_06 